Keywords: Aluminum Leaching Chromium Leaching

Retention: Permanent

\title{
Aluminum and Chromium Leaching Workshop Whitepaper
}

D. J. McCabe

R.A. Peterson*

J.A. Pike

W.R. Wilmarth

Publication date: April 25, 2007

*Pacific Northwest National Laboratory 


\section{Disclaimer}

This report was prepared as an account of work sponsored by an agency of the United States Government. Neither the United States Government nor any agency thereof, nor any of their employees, nor any of their contractors, subcontractors or their employees, makes any warranty, express or implied, or assumes any legal liability or responsibility for the accuracy, completeness, or any third party's use or the results of such use of any information, apparatus, product, or process disclosed, or represents that its use would not infringe privately owned rights. Reference herein to any specific commercial product, process, or service by trade name, trademark, manufacturer, or otherwise, does not necessarily constitute or imply its endorsement, recommendation, or favoring by the United States Government or any agency thereof or its contractors or subcontractors. The views and opinions of authors expressed herein do not necessarily state or reflect those of the United States Government or any agency thereof. 


\section{Summary}

A workshop was held on January 23-24, 2007 to discuss the status of processes to leach constituents from High Level Waste (HLW) sludges at the Hanford and Savannah River Sites. The objective of the workshop was to examine the needs and requirements for the HLW flowsheet for each site, discuss the status of knowledge of the leaching processes, communicate the research plans, and identify opportunities for synergy to address knowledge gaps. The purpose of leaching of non-radioactive constituents from the sludge waste is to reduce the burden of material that must be vitrified in the HLW melter systems, resulting in reduced HLW glass waste volume, reduced disposal costs, shorter process schedules, and higher facility throughput rates. The leaching process is estimated to reduce the operating life cycle of SRS by seven years and decrease the number of HLW canisters to be disposed in the Repository by 1000 [Gillam et al., 2006]. Comparably at Hanford, the aluminum and chromium leaching processes are estimated to reduce the operating life cycle of the Waste Treatment Plant by 20 years and decrease the number of canisters to the Repository by 15,000 - 30,000 [Gilbert, 2007]. These leaching processes will save the Department of Energy (DOE) billions of dollars in clean up and disposal costs.

The primary constituents targeted for removal by leaching are aluminum and chromium. It is desirable to have some aluminum in glass to improve its durability; however, too much aluminum can increase the sludge viscosity, glass viscosity, and reduce overall process throughput. Chromium leaching is necessary to prevent formation of crystalline compounds in the glass, but is only needed at Hanford because of differences in the sludge waste chemistry at the two sites. Improving glass formulations to increase tolerance of aluminum and chromium is another approach to decrease HLW glass volume. It is likely that an optimum condition can be found by both performing leaching and improving formulations.

Disposal of the resulting aluminum and chromium-rich streams are different at the two sites, with vitrification into Low Activity Waste (LAW) glass at Hanford, and solidification in Saltstone at SRS. Prior to disposal, the leachate solutions must be treated to remove radionuclides, resulting in increased operating costs and extended facility processing schedules. Interim storage of leachate can also add costs and delay tank closure. Recent projections at Hanford indicate that up to 40,000 metric tons of sodium would be needed to dissolve the aluminum and maintain it in solution, which nearly doubles the amount of sodium in the entire current waste tank inventory. This underscores the dramatic impact that the aluminum leaching can have on the entire system. A comprehensive view of leaching and the downstream impacts must therefore be considered prior to implementation.

Many laboratory scale tests for aluminum and chromium dissolution have been run on Hanford wastes, with samples from 46 tanks tested. Three samples from SRS tanks have been tested, out of seven tanks containing high aluminum sludge. One full-scale aluminum dissolution was successfully performed on waste at SRS in 1982, but generated a very large quantity of liquid waste ( 3,000,000 gallons). No large-scale tests have been done on Hanford wastes. Although the data to date give a generally positive indication that aluminum dissolution will work, many issues remain, predominantly because of variable waste compositions and changes in process conditions, downstream processing, or storage limitations. Better approaches are needed to deal 
with the waste volumes and limitations on disposal methods. To develop a better approach requires a more extensive understanding of the kinetics of dissolution, as well as the factors that effect rates, effectiveness, and secondary species. Models of the dissolution rate that have been developed are useful, but suffer from limitations on applicable compositional ranges, mineral phases, and particle properties that are difficult to measure. The experimental bases for the models contain very few data points.

A critical parameter that governs the rate of dissolution of aluminum is the form and particle size of the aluminum species. The two primary insoluble forms of aluminum present in the waste are gibbsite and boehmite, although there are also numerous minor and mixed species as well. Boehmite is difficult to dissolve, and gibbsite is relatively easy to dissolve in caustic. The dissolution rate of boehmite is the rate-limiting step in aluminum dissolution. The particle size and degree of crystallinity of each species also impact the dissolution rate, and viscosity, settling velocity, and filtration rates impact liquid-solid phase separation steps that follow dissolution. Minimal data exist on the speciation and physical properties of tank waste samples at either site. The fundamental problem is that the wastes largely begin as gibbsite, but gradually convert to boehmite or other mineral forms as the wastes age. Although the conversion has slowed in some tanks because they are relatively cool, other tanks remain at nearly $100{ }^{\circ} \mathrm{C}$, and are expected to continue to convert. Each tank, and even different regions or layers within a single tank, can have different compositions, particle sizes, and behaviors.

Interaction between the sites and researchers at the workshop was highly beneficial to developing an understanding of the issues surrounding aluminum and chromium leaching. The two sites have significantly different strategies for implementing aluminum dissolution, primarily because of a difference in facilities and schedules. Although some needs overlap, some are very different (e.g. corrosion and temperature limits). Solutions to the needs can overlap in common areas, and there is a need for collaboration. A fundamental understanding of the dissolution rates and parameters that affect it are important for both sites. Continued research is needed to ensure that the decreased cost projections for the DOE are realized. 


\section{Authors:}

D. J. McCabe, SRNL Advanced Characterization \& Process Research

Date

R.A. Peterson, Pacific Northwest National Laboratory

Date

J.A. Pike, Technology Integration and Process Development

Date

W.R. Wilmarth, SRNL Actinide and Chemical Technology

Date

\section{Approvals/Review:}

A.M. Murray, Manager, SRNL Environmental and Chemical Process Technology Date 



\section{Introduction}

A workshop was held in Atlanta, Georgia, January 23-24, 2007 to discuss the status of leaching constituents from High Level Waste (HLW) sludges at the Hanford and Savannah River Sites. The objective of the workshop was to examine the needs and requirements for the HLW flowsheet for each site, discuss the status of knowledge of the leaching processes, communicate the research plans, and identify opportunities for synergy to address knowledge gaps. This document is intended to give an overview of the state of knowledge of the aluminum and chromium leaching parameters and the identified issues and knowledge gaps, not to summarize each workshop presentation. Where needed for explanation, there is also additional background information and references provided that were not presented at the workshop (e.g. speciation of aluminum in Hanford samples).

Leaching of non-radioactive constituents from the sludge waste can reduce the burden of material that must be vitrified in the melter systems, resulting in reduced glass waste volume, reduced disposal costs, shorter processing schedules, and higher facility throughput rates. This leaching process is estimated to reduce the Defense Waste Processing Facility (DWPF) operating life cycle at Savannah River Site (SRS) by seven years and to decrease the number of canisters to be disposed in the Repository by 1000 [Gillam et al., 2006]. Comparably, the aluminum and chromium leaching processes are estimated to reduce the operating life cycle of the Waste Treatment Plant (WTP) at Hanford by 20 years and to decrease the number of canisters to be disposed in the Repository by 15,000 - 30,000 [Gilbert, 2007]. These efforts will thereby save the DOE billions of dollars in clean up and disposal costs.

The primary constituents targeted for removal by leaching are aluminum and chromium. It is desirable to have some aluminum in glass to improve its durability; however, too much aluminum can increase the sludge viscosity, glass viscosity, and reduce overall process throughput. Chromium has a finite solubility in glass, with excessive amounts causing formation of spinels or eskolaite that can settle in the melter or clog melter pour spouts [Perez et al., 2001]. Aluminum leaching is important to both sites, but chromium removal is only important at Hanford because a higher fraction of the chromium is insoluble in the sludge than in the sludge at SRS. As long as the chromium concentration can be maintained at less than $0.5 \mathrm{wt} \%$ in the glass, removal has little impact on sludge mass and no impact on glass quality.

Although a converse approach to solving this issue is to develop melters and glass formulations that can accommodate high aluminum loading, this approach was discussed in only a limited way at this workshop. While this approach is desirable, the optimum is to develop leaching processes and in parallel develop glass formulations that can tolerate higher aluminum and chromium levels within the limitations of current melter designs. This parallel path maximizes the opportunity for reducing the facility life cycle durations, canister count, and cost. A subsequent workshop is being planned to examine ways to optimize the aluminum and chromium tolerance in the vitrification process.

\section{Statement of Need}

There are several principal reasons to avoid sending the aluminum to the joule-heated HLW melters [Peeler, 2007]. First, high-aluminum sludges have a high viscosity, impacting the throughput of processes preceding the melter such as the washing and settling, evaporation, and mixing. Second, the larger mass of material fed to the melter requires more heat to evaporate the 
water that accompanies the sludge, thereby lowering the melt rate. Third, high aluminum causes the glass to be more viscous, slowing heat transfer, melt rate, and pour rate. Fourth, the high aluminum can cause nepheline formation in the poured glass as it cools, which impacts the glass durability. Finally, these physical and chemical properties of aluminum in the waste cause higher overall cost by increasing the facility life cycle and increasing the number of waste canisters produced. Similarly, chromium is a nuisance primarily because it forms crystals in the melter that can settle and interfere with melter performance and throughput, shortening the melter life, or can clog the pour spout [Perez et al., 2001].

\section{Site Needs/Flowsheets/Requirements}

Savannah River Site

At SRS, there are a limited number of tanks that contain appreciable amounts of high aluminum sludge [Gillam, 2006; Hamm et al., 2006]. Tanks 12H, 13H, 15H, 32H, 35H, and 39H contain about 1000 metric tons of aluminum, which represents $61 \%$ of the total aluminum in all the waste tank sludge. The current estimate of total sludge mass in the tanks has recently increased. The batches of sludge that have been processed in the Defense Waste Processing Facility (DWPF) have been observed to contain 50 to $100 \%$ more mass than originally estimated. The reasons for this discrepancy include: (1) the primary purpose of mass estimates was criticality control and hence were intentionally conservative; (2) estimates were based on canyon flow sheets and do not account for variations from the flowsheet; (3) re-work of some batches of material; and (4) early target assemblies had different aluminum contents [Hill et al., 2007]. As a result, the projected life cycle completion date moved to 2035. Aluminum leaching is needed to return the date to 2028 and meet the site treatment plan [Davis, 2007].

At SRS, the conceptualized process is to dissolve the aluminum in a dedicated Type III waste tank outfitted with up to four mixer pumps [Gillam, 2006]. This tank (assumed to be Tank 42H) is a 1.3 million gallon waste storage tank, equipped with a fully active ventilation system and cooling coils. The first step is to transfer unwashed sludge slurry ( $\sim 15 \mathrm{wt} \%$ solids $)$ into the process tank. With mixing, the sodium hydroxide solution is added, and the tank is heated using steam sparging to $85^{\circ} \mathrm{C}$. Temperature is maintained and the tank is continuously mixed for several days, with the duration dictated by composition and conditions. The tank contents are then allowed to cool and settle for at least fourteen days. The aluminum-rich supernate is then decanted and sent to another tank. The remaining sludge is rinsed with another more dilute sodium hydroxide solution, mixed, settled for at least fourteen days, and decanted. This rinsing, mixing, and settling is then repeated again, with an even lower concentration of sodium hydroxide solution. The aluminum-depleted sludge is then ready for transfer to the sludge washing tank, where more water is added to remove the soluble sodium salts to meet the DWPF feed requirements, and mixing and settling are repeated. The aluminum-rich aqueous supernate solutions are composited and sent to the feed tank for the Salt Waste Processing Facility (SWPF). There, the solution is decontaminated for ${ }^{90} \mathrm{Sr}$, actinides, ${ }^{137} \mathrm{Cs}$, and disposed to Saltstone. Since the SWPF is not scheduled for start up for several years, the decanted supernate must be stored in the SRS tank farms, and there is very limited storage space available. 


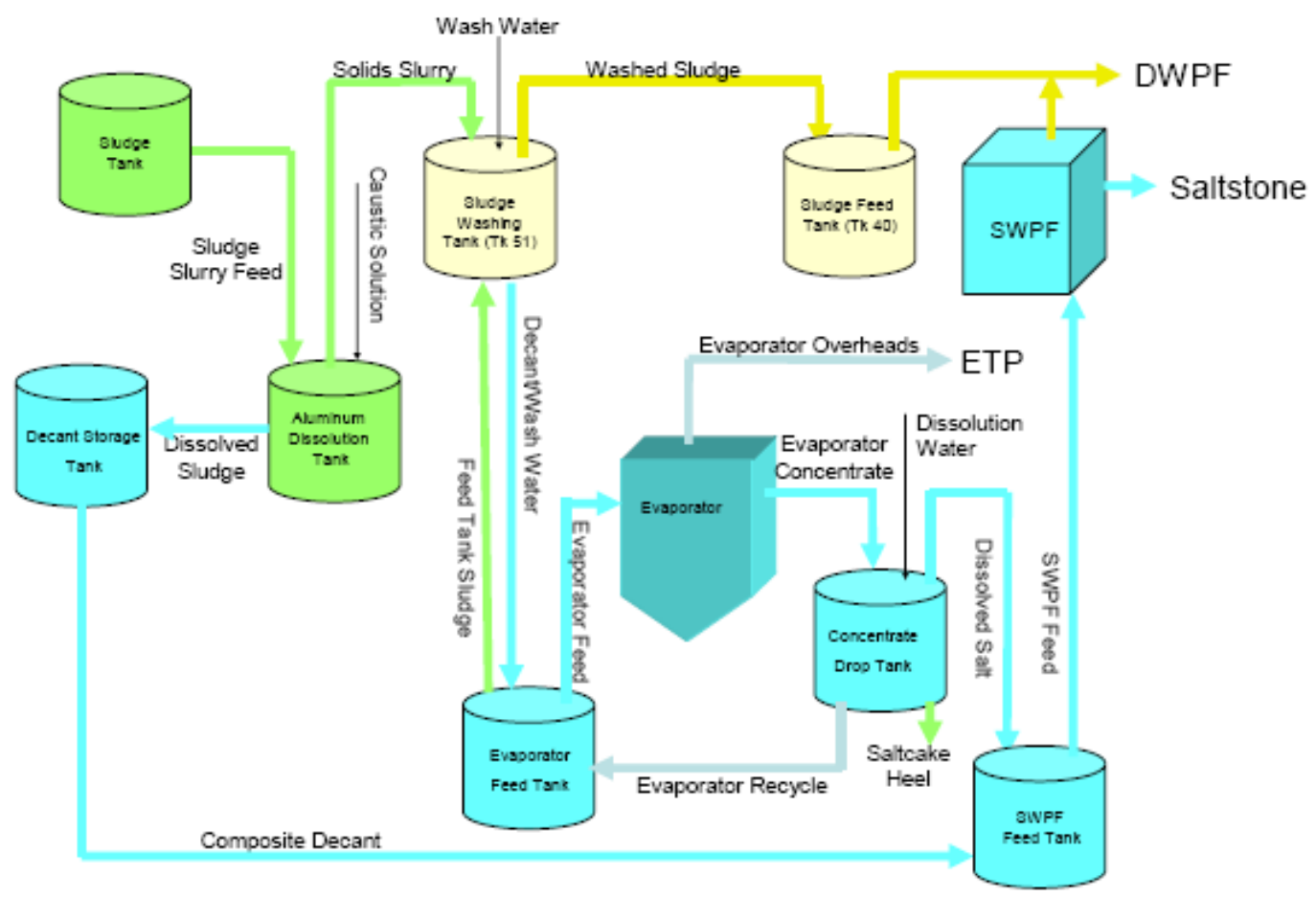

Figure 1. Preliminary SRS Flow-sheet for Aluminum Leaching [Pike, 2006]

The target for aluminum removal from these sludges is $75 \%$ of the total aluminum present, as either gibbsite or boehmite. The leaching process must actually dissolve a slightly higher fraction of the aluminum than $75 \%$, because some soluble aluminum always remains behind in the aqueous phase after sludge washing. Settling of the sludge only reaches about $20 \mathrm{wt} \%$ solids, so the remaining $80 \mathrm{wt} \%$ aqueous phase contains some amount of soluble aluminum. Removal of all the aluminum from all sludges is not desired, as it is needed to produce a durable glass. Blending of the leached sludge with other, non-leached sludges, will ensure an acceptable composition for feed to the DWPF. The minimum loading for aluminum in the glass waste form is $4 \mathrm{wt} \%$ (as aluminum oxide) or $3 \mathrm{wt} \%$ with an upper limit on the alkali content [Brown et al., 2006]. The maximum loading is not specifically defined as it is a function of other constituents in the glass.

\section{Hanford Waste Treatment Plant}

At Hanford, the majority of the waste contains insoluble aluminum and chromium. The insoluble aluminum is present in roughly three equal parts of sodium aluminate, gibbsite, and boehmite. The insoluble chromium species are present in the +3 oxidation state $\left[\mathrm{Cr}^{+3}\right]$. The form of the insoluble chromium has not been defined and may be present as either chromic hydroxide $\left[\mathrm{Cr}(\mathrm{OH})_{3}\left(\mathrm{H}_{2} \mathrm{O}\right)_{3}\right]$, chromic oxyhydroxide $[\mathrm{CrOOH}]$ or chromic oxide $\left[\mathrm{Cr}_{2} \mathrm{O}_{3}\right]$. The current process requirements at Hanford place glass loadings for aluminum oxide $\left[\mathrm{Al}_{2} \mathrm{O}_{3}\right]$ at $11 \mathrm{wt} \%$ and chromic oxide $\left[\mathrm{Cr}_{2} \mathrm{O}_{3}\right]$ at $0.5 \mathrm{wt} \%$ in glass. Without removal of these elements, 30,000 - 40,000 HLW glass canisters would be produced at Hanford, based on estimated glass loadings. With effective removal of aluminum and chromium from the High Level Waste (HLW) fraction, the number of canisters can be reduced to $10,000-15,000$ [Gilbert, 2007]. 
The sodium aluminate is water soluble and relatively easily removed from the HLW fraction, while the gibbsite and boehmite are soluble in caustic. However, the kinetics of dissolution of gibbsite and boehmite at ambient temperatures are relatively slow. Temperatures of at least 50$60{ }^{\circ} \mathrm{C}$ are required to rapidly dissolve gibbsite, while boehmite requires significantly higher temperatures to achieve dissolution rates within the time frame needed for process operation

The chromium must be oxidized from relatively insoluble chromic ion [Cr(III)] to soluble chromate ion $[\mathrm{Cr}(\mathrm{VI})]$. This oxidation can be achieve through air oxidation, however the kinetics are slow. Therefore, the WTP has chosen to add permanganate to oxidize the chromium. This oxidation of the trivalent chromium with permanganate increases the kinetics of the dissolution, and the byproduct manganese oxide is highly soluble in the glass.

In the WTP baseline flow sheet, sludge solids are first recovered from various single shell and double shell tanks. During the retrieval process, incidental blending of the sludge occurs, resulting in blending of the gibbsite, boehmite and various chromium phases. This blended feed slurry is then delivered to the WTP at a nominal solids concentration of $6 \mathrm{wt} \%$ (though this value may vary up to $16 \mathrm{wt} \%$ ). This slurry is then further blended with supernate retrieved from other tanks and the resultant blended slurry is then concentrated to $20 \mathrm{wt} \%$ solids by filtration. After concentration, caustic is added and the stainless steel tank is heated with steam to $100^{\circ} \mathrm{C}$ to dissolve the aluminum. The tank is held at temperature for at least eight hours. This process will effectively dissolve all of the gibbsite and roughly half of the boehmite. The slurry is then cooled and re-concentrated by filtration. Then the slurry is washed to dilute the caustic concentration. This washing step effectively removes the solubilized aluminum from the insoluble solids, and is required to prevent the potential solubilization of plutonium during the subsequent oxidation of chromium. (This solubilization of plutonium occurs under strongly oxidizing conditions if it is also in the presence of high hydroxide concentrations). After washing, sodium permanganate is added to oxidize the $\mathrm{Cr}(\mathrm{III})$ to $\mathrm{Cr}(\mathrm{VI})$. This slurry is allowed to react for six hours, then the slurry is again washed to separate the solubilized $\mathrm{Cr}(\mathrm{VI})$ from the sludge solids. This treatment dissolves approximately $80 \%$ of the chromium, which is sufficient. All of the filtered liquid phases are sent to ion exchange for cesium removal, and the insoluble solids are sent to the HLW melter system. 


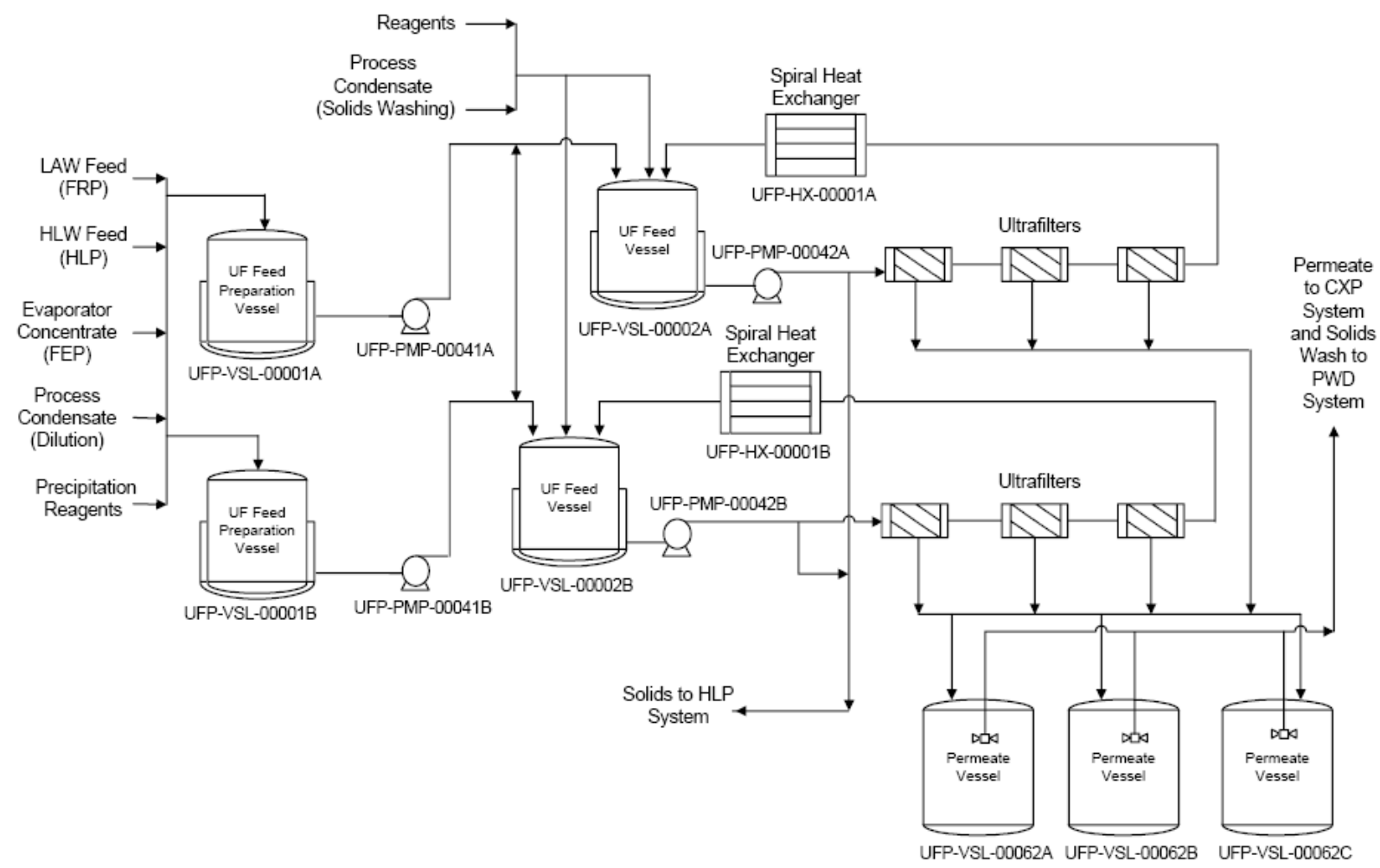

Figure 2. Simplified UFP Process Flow Diagram [Gilbert, 2007]

\section{Aluminum Chemistry and Dissolution Kinetics}

Aluminum speciation

Both SRS and Hanford have multiple forms of aluminum, with three primary forms: soluble aluminate ion (denoted as $\left.\mathrm{Al}(\mathrm{OH})_{4}{ }^{-}\right)$, gibbsite $\left(\mathrm{Al}(\mathrm{OH})_{3}\right)$, and boehmite $(\mathrm{AlO}(\mathrm{OH}))$. There are also smaller amounts of many other solid species including amorphous and crystalline aluminosilicates, diaspore, aluminum phosphate, and bayerite [Rapko, et al., 2000]. In one case, aluminum was also found to be in a solid solution phase associated with iron and manganese [Fondeur et al., 2004]. Gibbsite is easily dissolved in warm sodium hydroxide solutions. Boehmite is also soluble in sodium hydroxide, but requires higher temperatures and longer contact times to affect dissolution. It is generally the rate of boehmite dissolution that dictates the process conditions for leaching the wastes. The speciation of aluminum phases in the waste at the two sites is minimal. Generally, quantitative determination of the speciation is done by examining the dissolution rate of aluminum into a sodium hydroxide solution at around $80^{\circ} \mathrm{C}$, with the fast-dissolving portion assumed to be gibbsite and the slow dissolving portion boehmite. Qualitative speciation is also done using X-ray Diffraction. Only a few samples have been examined at SRS. Over forty radioactive waste samples have been examined at Hanford. The aluminum dissolution rate also is impacted by the particle size, speciation, impurities, degree of saturation, ionic strength, temperature, agitation rate, pressure, and other parameters [AddaiMensah, 2007]. This complex blend of parameters cannot be developed from elementary theory, so experimental data must be obtained [Addai-Mensah, 2007]. Additional parameters that can impact the processing rate include viscosity, settling velocity, and filtration rates. 
Minimal data exist on the speciation and physical properties of tank waste samples at either site. Leaching impacts on the physical properties and behaviors of the remaining sludges have been measured on only a few samples. These parameters are critical to subsequent processing, such as settling, filtration, and pumping, but are not well known.

The thermodynamic equilibrium condition for aluminum dissolution is reasonably well known and can be modeled with currently available software. The total or final solubility of pure aluminum species in pure sodium hydroxide is well known. Introduction of other insoluble and soluble species are in good agreement with the models as well, with a few exceptions [Smith, et al., 2007].

\section{Dissolution Rate Models}

It is important to be able to predict the rate of dissolution of aluminum at both SRS and Hanford. This prediction permits projection of the time needed to dissolve a certain fraction of aluminum from a batch of sludge, and ultimately determines the throughput of the process. It is typically undesirable to achieve $100 \%$ dissolution of boehmite because of the long times required, and it is also undesirable to remove the aluminum completely because it contributes to the glass durability. The models focus on dissolution rates of boehmite only, because it is typically ratelimiting. Dissolution of gibbsite is typically fast under conditions used. At SRS, the dissolution is done at lower temperature because it is in a carbon steel waste tank, and therefore takes longer, with typical dissolution cycles taking a few weeks. This processing time extends the duration of pump operation and delays sludge batch feed preparations. At Hanford, the dissolution cycles are typically eight hours. Improving the predictability of the aluminum dissolution rate would improve the ability to plan sludge batch preparation time and potentially prevent delays.

The approach to dissolution rate predictions at SRS used a generalized rate equation developed to model dissolution of minerals as a starting point for describing the dissolution of aluminum hydroxide solids in tank waste. Palanori and Kharaka [2004] describe a generalized rate model in the form shown by Equation 1:

$$
\frac{\mathrm{dm}}{\mathrm{dt}}=-(\mathrm{S})\left(\mathrm{Ae}^{-\frac{\mathrm{E}}{\mathrm{RT}}}\right) \mathrm{f}\left(\mathrm{a}_{\mathrm{i}}\right) \mathrm{g}\left(\Delta \mathrm{G}_{\mathrm{r}}\right) \quad \text { Eqn. } 1
$$

where:

$$
\begin{array}{ll}
\mathrm{dm} / \mathrm{dt}=\text { Dissolution rate, } \text { gmol solid } / \mathrm{hr} \\
\mathrm{S}=\quad \text { Solids surface } \text { area, } \mathrm{m}^{2} \\
\mathrm{~A}=\quad \text { Dissolution reaction pre-exponential factor, gmol solid } / \mathrm{m}^{2}-\mathrm{hr} \\
\mathrm{E}=\quad \text { Dissolution reaction activation energy, cal/gmol } \\
\mathrm{T}=\quad \text { Absolute temperature, } \mathrm{K} \\
\mathrm{R}=\quad \text { Gas constant, cal/gmol-K } \\
\mathrm{f}\left(\mathrm{a}_{\mathrm{i}}\right), \mathrm{g}\left(\Delta \mathrm{G}_{\mathrm{r}}\right) \text { are functions of component activities and Gibbs free energy. }
\end{array}
$$

Since the anticipated process conditions are known for SRS because of equipment and process limitations, several assumptions can be made to simplify the calculations and parameters. The simplified equation for the specific dissolution conditions and assumptions for the SRS process include: 
- Sufficient solids and liquid mixing is provided,

- Aluminum hydroxide solids are primarily present in the form of boehmite,

- The dissolution endpoint composition is selected such that the solubility limit does not influence the dissolution rate at the dissolution operating temperature (i.e., the process is far from saturated in aluminum),

- The change in liquid phase water mass is negligible over the dissolution time period,

- The operating temperature is constant over the dissolution time period, and

- The liquid phase sodium hydroxide activity is approximately proportional to the molal concentration of free hydroxide ion in solution.

The result of the simplifications assumes that any gibbsite in the slurry will tend to dissolve quickly with the remaining boehmite following this model [Pajunen, 2006]:

$$
\mathrm{t}=\frac{\alpha \mathrm{F}(\mathrm{wf}, \alpha)}{\left(2 \times 10^{15}\right) \sqrt{\mathrm{C}_{\mathrm{OH}}^{0}}} \mathrm{e}^{\frac{14800}{\mathrm{~T}}}
$$

Eqn. 2

where :

$\mathrm{t}=$ Dissolution time, $\mathrm{hr}$

$\mathrm{F}(\mathrm{wf}, \alpha)=\frac{1}{\sqrt{\alpha(\alpha-1)}} \operatorname{Ln}\left|\frac{(\sqrt{\alpha}-\sqrt{\alpha-1})(\sqrt{\alpha-1+\mathrm{wf}}+\sqrt{\alpha-1})}{(\sqrt{\alpha}+\sqrt{\alpha-1})(\sqrt{\alpha-1+\mathrm{wf}}-\sqrt{\alpha-1})}\right|$

$\alpha=$ Mole ratio at initial conditions of free $\mathrm{OH}$ ion in the liquid phase relative to $\mathrm{Al}$ in the solid phase, dimensionless

$\mathrm{C}_{\mathrm{OH}}^{0}=$ Initial liquid phase concentration of free $\mathrm{OH}$ ion in molal units, gmol $/ \mathrm{kg}$ water

$\mathrm{T}=$ Dissolution operating temperature, $\mathrm{K}$

$\mathrm{wf}=$ Weight fraction of initial $\mathrm{Al}$ remaining in solids at the conclusion of the dissolution process, dimensionless

These simplifications result in several limitations to its applicability, but they are within the currently anticipated operating window for SRS. The simplified model is applicable for hydroxide ion concentrations less than $6.8 \mathrm{M}$. A shift in reaction order occurs above this concentration and the rate equation would be expected to over-estimate time needed to dissolve aluminum while the liquid phase is at free hydroxide ion concentration greater than $6.8 \mathrm{M}$.

The simplified model is based on the assumption that the liquid phase sodium hydroxide activity is approximately proportional to the molal concentration of free hydroxide ion in solution. As a result, the batch dissolution model will have difficulty describing a set of initial conditions where the initial mole ratio of sodium hydroxide to aluminum is small (e.g., $\alpha=2)$ in combination with an initial liquid phase sodium hydroxide concentration that exceeds 5 to 6 gmol sodium hydroxide per kilogram of water.

The last simplification is that the dissolution end point is not near or at the saturation limit of the final solution. Approaching the saturation limit would influence the dissolution rate significantly. Specifically, as the aluminum in solution approaches saturation, the dissolution rate slows down and the rate equation would under-predict the time required. Selected process conditions will avoid approaching or reaching saturation, thus, avoiding the concentrationdependent rate reduction.

An alternative method for predicting the dissolution rate, with fewer compositional limitations on applicability, can also be used. Scotford et al.[1971, 1972] measured the kinetics of 
dissolution for boehmite at various temperatures and sodium hydroxide concentrations. They found that the reaction was half-order with respect to hydroxide concentration and followed an Arrehnius equation for temperature dependence. Skoufadis et al. [2003] described the precipitation of boehmite as second order with respect to aluminate concentration. By starting with the reaction rate and equilibrium condition equations and by assuming a constant hydroxide concentration during leaching, the following relation for a reversible surface reaction is derived:

$$
\begin{aligned}
& -\frac{d C_{B}}{d t}=k_{s} C_{O H}^{1 / 2}\left[1-\left(\frac{C_{A l, o}+C_{A l, s} X_{B}}{C_{A l, e}}\right)^{2}\right] \\
& k_{s}=A e^{-\frac{E}{R T}}
\end{aligned}
$$

Eqn 4

$$
\text { where } \begin{aligned}
C_{B}= & \text { concentration of Boehmite on the particle surface }\left(\mathrm{mol} \mathrm{m}^{-2}\right) \\
k_{S}= & \text { surface reaction rate }\left(\mathrm{mol}^{0.5} \mathrm{~L}^{0.5} \mathrm{~m}^{-2} \mathrm{sec}^{-1}\right) \\
R= & \text { gas constant }\left(8.314 \mathrm{~J} \mathrm{~mol}^{-1} \mathrm{~K}^{-1}\right) \\
A= & \text { frequency factor }\left(\mathrm{mol}^{0.5} \mathrm{~L}^{0.5} \mathrm{~m}^{-2} \mathrm{sec}^{-1}\right) \\
E= & \text { Activation energy }\left(123 \mathrm{~kJ} \mathrm{~mol}^{-1}\right)^{[\text {Scotford } 1971,1972]} \\
T= & \text { reaction temperature }(\mathrm{K}) \\
C_{O H}= & \text { hydroxide concentration in the leach solution }\left(\mathrm{mol} \mathrm{L}^{-1}\right) \\
C_{A l, o}= & \text { initial aluminate concentration } \left.(\mathrm{mol} \mathrm{L})^{-1}\right) \\
C_{A l, s}= & \text { initial molar quantity of boehmite in the solid phase per volume of leach solution } \\
& \text { (mol L-1) } \\
C_{A l, e}= & \text { aluminate concentration at equilibrium (mol L } \left.\mathrm{L}^{-1}\right) \\
X_{B}= & \text { conversion of boehmite (mass fraction). }
\end{aligned}
$$

Solving Equation 3 produces an equation describing the dissolution of boehmite based on a model system of a distribution of various length shrinking platelets. A more detailed discussion of the development of this solution is available [Peterson, et. al, 2007]

$$
X_{B}^{*}=1-\int_{L_{t}}^{L_{\max }}\left[1-\frac{C_{A l, e}}{C_{A l, s}} \tanh \left(\frac{k_{s} C_{O H}^{1 / 2} C_{A l, s}}{\rho_{B} L C_{A l, e}} t\right)\right] \frac{1}{\beta^{\alpha} \Gamma(\alpha)} L^{\alpha-1} e^{-\frac{L}{\beta}} d L \quad \text { Eqn } 5
$$


In this equation, $L_{\max }$ is the maximum length of the initial undissolved plates; $L_{t}$ is the largest particle completely dissolved at time, $t$, and is given as follows:

$$
L_{t}=\frac{k_{s} C_{O H}^{1 / 2} C_{A l, s}}{\rho_{B} C_{A l, e} \operatorname{atanh}\left(\frac{C_{A l, s}}{C_{A l, e}}\right)} t \quad \text { Eqn } 6
$$

As Gbor et al.[2004] states, $L_{\max }$ should be chosen such that at least $99.9 \%$ of the particle volume in the distribution is mathematically considered. For the modeling results presented in this work, $L_{\max }$ was set to $10 \mu \mathrm{m}$, which meets the criterion shown below:

$\int_{0}^{L_{\max }} \frac{1}{\beta^{\alpha} \Gamma(\alpha)} L^{\alpha-1} e^{-\frac{L}{\beta}} d L \geq 0.999 \quad$ Eqn 7

Although these models reflect the basic dissolution behaviors, they have been applied to actual waste sample performance for only a few samples. The range of the conditions tested encompassed the operating conditions planned for Hanford, but the dataset is limited when compared to plans at SRS. Most of the testing on Hanford samples was done only under a specific set of defined conditions and did not obtain kinetic data (only end-point), and are not detailed enough to be usable as for a kinetic model basis. Similarly, the SRS data is linked to experimental results, but there were only a few samples tested. There is moderate confidence in the ability of these models to predict the dissolution kinetics under conditions within the range of test conditions, but lower confidence when conditions such as temperature and concentrations are outside the range. The SRS model is heavily based on the 1982 in-tank demonstration, so intrinsically includes the parameters that affected the dissolution rate for that tank, such as particle size, but does not address those parameters separately. The SRS process does have more flexibility regarding duration of the dissolution step, typically a few weeks, than Hanford, which is eight hours. Further, the extended duration of the SRS process allows monitoring by sampling and analysis, giving real-time dissolution rate data, rather than relying on a prediction.

Models based on laboratory experiments are also intrinsically based on nearly perfect mixing. Mixing is a key parameter that can control the dissolution rate if inadequate [Addai-Mensah, 2007]. Further testing of the kinetics of dissolution with real waste samples, and the impact of mixing are needed to improve the predictability and control of the process. The impact of other species, both soluble and insoluble, is not defined in either model.

\section{Overlap with the Aluminum Industry}

To a very limited extent, the leaching of aluminum overlaps with the first step in the commercial Bayer process used to refine aluminum from bauxite ore [Ullmann, 2003].

Typically, the Bayer process is operated at temperatures exceeding $140{ }^{\circ} \mathrm{C}$, requiring the use of pressure vessels to avoid evaporative loss of water [Ullmann, 2003]. The radioactive leaching processes are done at ambient pressure, therefore lowering the achievable temperature. Further, the baseline leaching at SRS is performed in a carbon steel tank, further lowering the target temperature $\left(85^{\circ} \mathrm{C}\right)$ due to several other restrictions, primarily concerning minimizing corrosion. 
These lower temperatures at SRS dramatically increase the time required to dissolve the boehmite from the waste versus the commercial process. The baseline leaching at Hanford is performed in a dedicated stainless steel tank, allowing slightly higher temperature $\left(100{ }^{\circ} \mathrm{C}\right)$.

The Bayer process is also run at the saturation point of the aluminum at the elevated temperature, so that when the liquid is cooled, the maximum amount of aluminum can be precipitated and recovered. The cooling is closely controlled to optimize growth of particulates, and is often seeded with aluminum hydroxide [Addai-Mensah, 2007]. The cooling is often performed in flash tanks to remove water and increase the aluminum concentration in the liquid phase [Ullmann, 2003]. The primary function of the Bayer process is to maximize precipitation of the solids to ensure good aluminum recovery. The highly saturated liquor is then recycled and reused for a subsequent batch to minimize caustic usage and maximize aluminum recovery. The radioactive processes are run at much less than the saturation point at elevated temperature, and are even slightly less than the saturation point at ambient temperature, specifically to avoid precipitation. Precipitation of solids would interfere with the performance of downstream processes. If the aluminum solids were to re-precipitate at SRS, they would be filtered out in the Actinide Recovery Process and return to DWPF anyway, eliminating any gain. If the aluminum solids were to precipitate at Hanford, the ion exchange bed would be blinded with solids and would not function.

The Bayer process is run with a minimal amount of other soluble salts present in the stream, which interfere with the aluminum precipitation step [Ullmann, 2003, Addai-Mensah, 2007]. The radioactive waste stream contains large concentrations of many other soluble salts. While in theory these could be washed out first, this approach substantially increases the quantity of liquid that requires subsequent storage, treatment, and disposal. The additional salt is actually a benefit for the radioactive waste processes, by increasing the solubility of aluminum; whereas soluble salts are considered "interfering" species in industry because they increase the aluminum solubility and thereby reduce aluminum precipitation and recovery.

The equipment used in the commercial industry is dramatically different from the equipment used in the radioactive environment. The commercial process typically has hands-on maintenance equipment in specifically designed tanks. At SRS, the baseline process is to perform the leaching and settling in waste tanks that were not designed for this purpose. At Hanford, the equipment is specifically designed for the process, but is remotely controlled and maintained.

The commercial process uses bauxite ore as the feed to the process, which is relatively homogeneous, and composition can somewhat be controlled or at least well characterized. Conversely, waste components at both sites vary by original source, and contain many elements and species that are not in bauxite ore. The impact and fate of many of these species is not known.

The only significant overlap of the commercial Bayer process with the radioactive flow-sheets is that the aluminum is dissolved in sodium hydroxide solution, although the concentrations and temperatures are significantly different. As a result, the industry-generated chemistry, kinetics, and behavioral characteristics in the range of SRS and Hanford process conditions are somewhat 
useful, but not comprehensive. Processing concepts may offer insight to innovative variations, but industrial processes are not directly applicable.

\section{Comparison of Hanford and Savannah River}

There are some similarities but also significant differences with the ways that Hanford and SRS are implementing sludge leaching. A large part of the difference is due to the scale of the dissolution and materials of construction, with SRS performing the dissolution in 1.3 million gallon carbon steel tanks, and WTP using 40,000 gallon stainless steel digester. This difference causes the time scales of both dissolution and cooling to be different, and impacts the allowable chemistry because of tank corrosion limits.

SRS is targeting only aluminum removal, and Hanford is targeting both aluminum and chromium. As stated above, this difference is because of a larger fraction of insoluble chromium in the sludge at Hanford versus SRS sludge. The origin of the waste sludges at the two sites is different, with only the Purex process run at SRS. There are essentially only two waste types at SRS, referred to as "Purex" and "HM". Most of the high aluminum is in the HM sludge, and there are a total of seven tanks that contain HM sludge. The fractions of gibbsite and boehmite in HM sludges are not well known and some data conflict, which may be due to nonrepresentative sampling. These discrepancies lead to large uncertainty in the assumed process conditions and the resulting projected effectiveness. At Hanford, there are numerous waste types ( $>40$ total; [Meacham, 2003]), including Redox, which is $90 \%$ aluminum (mostly as boehmite), and Cladding waste from Purex, which is $90 \%$ aluminum (mostly as gibbsite). The gibbsitecontaining wastes have higher leach factors (defined as the concentration of dissolved aluminum divided by the total amount in the solids when tested under a specific test condition [Meacham, 2003]) versus the boehmite-containing wastes. As the wastes have aged in the tanks, conversion from gibbsite to boehmite can occur, with the rate dependent on the temperature and caustic content. For the tanks that are well below boiling, this conversion is thought to be slow. SRS tanks 32,35 , and 39 remain at nearly $100^{\circ} \mathrm{C}$, and so any remaining gibbsite probably continues to convert to boehmite.

The time scale for the dissolution processes is very different. At SRS, the leaching is done for several days and at Hanford only for eight hours. Cooling the solution also takes several days at SRS, and 40 hours at Hanford.

The scale of the impact at SRS is much smaller than at Hanford. The total aluminum targeted for leaching at SRS is 1000 metric tons compared to 4,400 metric tons at Hanford.

The methods of mixing the sludge and sodium hydroxide solution during leaching and after cooling are different at the two sites. The SRS process uses mixer pumps in the 1.3 million gallon tanks, and Hanford uses an agitator in the 40,000 gallon digester. At SRS, the cooled leachate liquor is transferred to another waste storage tank, which may or may not have agitation capabilities, but is not normally agitated continuously. At Hanford, the filtered leachate liquor is temporarily stored in an un-agitated 22,000 gallon tank. In either case, if the leachate liquor is supersaturated, it can precipitate into a hardened mass if un-agitated [Addai-Mensah, 2007], causing problems for subsequent retrieval and processing. 
The solid-liquid separation step at SRS is settling and decanting, whereas it is crossflow filtration at Hanford. At Hanford, there is a wide range of feeds that are blended to produce a spectrum of feeds to the WTP. Thus, the WTP needs a more proactive solid-liquid separation step. The physical properties of the leached sludges can impact the different solid-liquid separation steps in different ways.

A significant consideration at SRS is the storage volume of the aluminum-rich stream. Since the DWPF is operating, the sludge feed needs to be prepared to keep pace; however, the liquid waste treatment facility (SWPF) will not be operational for several years, and there is virtually no room in the tank farms to store the leachate liquor or wash water. As such, sludge batch preparation plans are formulated to minimize the amount of high aluminum sludge processed before SWPF starts up. If a process is deployed before SWPF startup, the decanted aluminum-leachate at SRS will be stored for years prior to treatment and disposal, and could be mixed with other aqueous waste streams in the interim, potentially causing precipitation. At Hanford, the leachate liquor is treated and disposed immediately. The current projection for the quantity of sodium hydroxide needed to dissolve the aluminum and maintain its solubility through the rest of the WTP facility is up to 40,000 metric tons of sodium [Gilbert, 2007]. This quantity is a $83 \%$ higher sodium burden for the system than is present in all the Hanford waste tanks today, substantially impacting the facility throughput and LAW glass volume. Strategies are needed at both sites for reducing the volume of material that must be stored and processed to meet operating schedules.

The product disposition is different at the two sites. At SRS, the aluminum-rich stream is decontaminated by solvent extraction, mixed with grout, and disposed in the Saltstone Facility. At Hanford, the leachate from both processes is decontaminated using ion exchange, mixed with glass-forming chemicals, and vitrified in a LAW melter. The leaching process increases the quantity of material that must be decontaminated and disposed, but the processing of this material is likely much less expensive than disposing the aluminum as HLW in glass canisters shipped to the Repository.

The potential for formation of an insoluble form of aluminum, sodium aluminosilicate (NAS), can be an issue at both sites. At SRS, there is limited silicon in the sludge wastes, but there is a large amount of silicon in the recycle from DWPF that returns to the Tank Farms. Current practice will keep these streams segregated and minimize NAS formation, but the NAS formation still has a dramatic impact on the throughput of the $2 \mathrm{H}$ evaporator system. A separate program is underway to examine ways to deal with this evaporator system that is outside the scope of this document. At Hanford, there is potential for NAS formation in the aluminum dissolution vessels because of the silicon in the recycle from the melters. The primary identified location for potential NAS formation is in the treated LAW evaporator, although the effect is limited by the moderate temperature of the evaporator.

Although one of the primary objectives, aluminum removal, is the same at the two sites, the flow sheets, equipment, waste composition, and disposition paths cause substantial differences in the method to achieve success.

\section{Actual Waste Dissolution Performance}

$\underline{\text { SRS Tank Samples }}$

Limited testing has been performed with samples from Tanks $11 \mathrm{H}, 12 \mathrm{H}$, and $15 \mathrm{H}$ [Fondeur, et al., 2004, Woolsey, 1980, Jones, 1981, Eibling, 1982, Spencer et. al, 2003]. Conditions of each 
test varied widely, with varying hydroxide concentrations, temperatures, and durations. Some conditions used in the experiments exceeded the hydroxide content and/or temperature limits currently achievable for an in-tank process. Dissolution was generally successful, with $65-95 \%$ of the aluminum dissolved.

\section{SRS In-Tank Demonstration}

Full-scale aluminum dissolution was performed in a waste tank at SRS in 1982 [Gillam, 2006b, Ator, 1984]. Sludge from Tank $15 \mathrm{H}$ was transferred to Tank $42 \mathrm{H}$, and settled to a final volume of about 64,000 gallons. Sodium hydroxide solution was added over a period of 21 days, and some salt solution was added as a source of liquid and caustic to minimize added caustic. The tank was heated with steam and mixed with slurry pumps for five days at $83-85^{\circ} \mathrm{C}$. The slurry was then settled and the leachate liquor was decanted. The slurry was washed three times. The mixing pumps leaked a substantial amount of water into the tanks as well, enough to nearly double the volume of liquid during the dissolution step. The process successfully removed $79 \%$ of the aluminum from the sludge, but generated 2,975,000 gallons of liquid. Other issues at the time included difficulty of the ventilation system in handling the excessive amount of liquid in the vapor, and settling of the resulting sludge was slower than expected.

\section{Hanford Tank samples}

Caustic-leach experiments were first performed on actual Hanford tank sludge samples in FY 1993. The original caustic-leaching experiments were performed as a prelude to acid dissolution of the sludge solids, with the intent that the acid-dissolved fraction would be processed through solvent extraction to separate the very small mass fraction of the radioactive elements (the transuranics [TRUs], ${ }^{90} \mathrm{Sr}$, and ${ }^{137} \mathrm{Cs}$ ) from the bulk mass of non-radioactive components [Lumetta et al. 1996a]. In this respect, caustic leaching was meant to remove the large amount of aluminum from the waste, thus reducing the nitric acid demand and simplifying the solvent extraction feed. However, subsequently, caustic leaching was chosen as the baseline method for Hanford tank sludge pretreatment; this process was sometimes referred to as "Enhanced Sludge Washing" [Lumetta et al. 1998a]. Following this decision, caustic-leach tests were performed under a standard set of conditions at the Pacific Northwest National Laboratory (PNNL) and Los Alamos National Laboratory (LANL); these tests were conducted from1995 through 1997 [Lumetta et al, 1994, Lumetta et al., 1996, Lumetta et al., 1997, Lumetta et al., 1998, Lumetta et al., 1998b, Lumetta et al., 2001, Temer et al., 1995, Temer et al., 1996, Temer et al., 1997]. In subsequent years, a limited number of parametric caustic-leaching experiments were performed at PNNL and also at Oak Ridge National Laboratory (ORNL). Upon establishment of the Hanford WTP project, a limited number of laboratory-scale caustic-leaching experiments were performed using a standard testing protocol, but these were generally focused on processing double-shell tank (DST) wastes rather than the single-shell tanks (SST) where the bulk of the sludge is stored.

To date, samples from 46 different tanks have been tested for aluminum dissolution, and ten for oxidative leaching [Certa, 2007]. These tests provide the basis for the range of expected performance from the WTP. These data are used as part of the Hanford Tank Waste Operations Simulator (HTWOS) model to project the effectiveness of dissolution. The model factors in the Best Basis Inventory (BBI) compositions, blending, and facility operations to predict the process and calculate the glass product quantity. This model shows the dramatic impact that leaching of aluminum and chromium can have on the HLW glass volume, as well as the impact of blending, 
retrieval sequence, and recycle streams. It is useful as a tool for process control and predicting glass volume, but is not intended to be a chemistry equilibrium or kinetics model, and leach factors are based on the experimental dataset available.

\section{Status of R\&D}

General

The rates of dissolution of gibbsite and boehmite from the waste sludge mixtures are moderately well known in the range of $80-100{ }^{\circ} \mathrm{C}$. Outside of this temperature range, the data are much more sparse. What is not known is the speciation and relative distribution of aluminum compounds in the waste, particularly at SRS. Neither site has much information regarding the particle size of the aluminum-containing solids, which strongly influences the dissolution rate. Because of the differences between samples regarding speciation, distribution, and particle size, creating simulants that accurately represent actual waste behavior is difficult.

Actinide behavior has been monitored in many dissolution tests, with results indicating that plutonium sometimes dissolves, and sometimes does not. While the levels that dissolve have not exceeded the allowable limits, the chemistry of dissolution is not well enough understood to predict behavior in all conditions. Further, selective dissolution of plutonium or uranium away from their poisons in the sludge (manganese and iron) could become a concern for downstream processing of the leachate, depending on the degree of dissolution, quantity, and isotopic distribution of materials involved. Dissolution of uranium and neptunium has been found to be non-negligible [Nash, et al., 2007]. Complexants that are present in some Hanford wastes can have significant impacts on actinide behavior during leaching, but these are generally soluble and are washed out prior to oxidative leaching. Even without complexants, powerful oxidants can increase solubility of plutonium and americium in high hydroxide solutions. The different waste types have different performance However, the manganese (II) oxide formed during oxidative leaching seems to help control the solubility of the plutonium species [Nash et al., 2007]. Long term stability of these soluble species is unlikely in the absence of complexants or residual oxidizers, especially soluble forms of americium, although this behavior has only been minimally examined.

Incorporation of aluminum into the glass matrix has not been optimized [Peeler, 2007]. Each waste sludge is somewhat unique in chemistry, and the glass formulation is currently tailored based on specific experiments. There is a strong correlation of tolerance for aluminum with the alkali content $\left(\mathrm{Na}^{+}\right)$, which can be manipulated somewhat by washing. It is believed that there is some margin in glass compositions for improving aluminum loading, generally by manipulating the frit chemistry, trim chemical addition, or sludge blending. Not only is the glass chemistry important, but the rheology of the sludge as it is being processed strongly influences the facility throughput. Rheological properties of waste mixtures at SRS are measured for each waste type, but are not predictable with current information. Further, over washing the sludge to improve aluminum solubility in the glass can negatively influence the rheological properties of the material, impacting the throughput of the pre-treatment process steps. Viscosity of the glass in the melter is also important, and is impacted by the concentration of aluminum in the melt. The rheology of the melt is also not predictable and must be measured experimentally with each formulation. A detailed listing of plans and needs for melter performance is beyond the scope of this document, and will be addressed in another workshop. 


\section{$\underline{\text { SRS }}$}

The total mass of sludge, aluminum-containing or not, is a key parameter at SRS. The recent rebase-lining of the quantity of sludge in the tanks indicates several more years of DWPF operation may be required, and may generate many more glass canisters than originally planned. The overall research and development program will incorporate this information as part of the baseline to determine ways to minimize the impact. Characterization of the sludges in the tanks is a key first step in this endeavor, and will be used to determine if these past observations are consistent with future tank behaviors to enable better planning.

\section{Hanford}

The dissolution rate for the boehmite containing waste from the REDOX process has been measured for multiple tank waste samples. However, characterization of the solid phase for these samples has been limited. Thus, development of accurate simulants of these phases is difficult.

The dissolution rate for the gibbsite-containing waste has not been measured accurately for Hanford wastes. Most of the prior tests with samples that contained a significant fraction of gibbsite were performed at elevated temperatures $\left(100^{\circ} \mathrm{C}\right)$ such that the gibbsite dissolved faster than accommodated by the sampling frequency. Additional tests with more frequent samples or lower temperature - will be required to obtain accurate gibbsite dissolution rate data. For sludges that are primarily gibbsite, knowing the gibbsite dissolution rate could permit faster processing, since the parameters and plans are generally set up for the slower boehmite dissolution rate.

The reaction rate for the permanganate with chromium has not been determined for actual waste samples. Prior testing has only observed the final performance. No intermediate rate data have been obtained. Similar to the rate limitations for gibbsite, if faster leaching occurs, the process rate could increase. Additional intermediate data will also be necessary to validate simulants for this process.

It has been demonstrated that plutonium does not solubilize significantly at very low hydroxide concentrations $(0.1$ to $0.25 \mathrm{M})$ and that a significant quantity of plutonium will solubilize at higher hydroxide concentrations $(3.0 \mathrm{M})$. This behavior is the reason for removal of the high hydroxide from aluminum leaching prior to oxidative leaching in the Hanford flow sheet. However, no testing has been done to date to evaluate intermediate caustic concentrations (for example $1.0 \mathrm{M}$ ). Solubilization of plutonium in the oxidative leaching process can lead to down stream criticality control issues if subsequent processes reduce the plutonium back to $\mathrm{Pu}(\mathrm{IV})$, thus reducing the solubility and producing plutonium-containing precipitates.

\section{Site R\&D Plans}

Savannah River Site

Experience has enabled SRS to move forward with developing a solids mass reduction process by dissolution of aluminum. However, both the baseline technology (aluminum dissolution) and any alternative technology require additional efforts to provide refinements for unit operations selection, design input, and operations. Science and technology needs are defined in the following three basic categories: 
WSRC-STI-2007-00168

April 25, 2007

- Process chemistry

- Process engineering

- HLW System interface

Process chemistry includes solubility, reaction kinetics and mass transfer properties necessary to finalize the conceptual design by establishing the physical and engineering property basis. Key decisions resulting from these activities include determining critically safe operating parameters, and operational parameters such as hydroxide concentration. Research and development plans include real waste testing to confirm rate predictions and solubility of aluminum as well as actinides. This effort will involve expensive and time consuming mixing and sampling of each waste tank, followed by characterization and chemical processing.

Process engineering data include the thermal and hydraulic transport properties, specific equipment attributes, material of construction, and requirements for temperature control. Key decisions resulting from these activities include selection of tank mixing technology, determining downstream process impacts, and finalization of the process flowsheet parameters. R\&D plans include mixing simulations and tests to determine viability of low cost pump systems, real waste tests for effect on sludge settling rates, corrosion tests to identify any temperature limitations, investigation of viable in-tank chemical probe for aluminum content of liquid phase, and engineering design evaluations of the waste tank ventilation, heating, and cooling systems under process conditions.

Additional development and testing will be completed to assure that the feed and product interfaces of the sludge mass reduction process are maintained with the HLW Tank Farm, DWPF and Saltstone. The issues of concern are assurance of glass qualifications, waste feed blending and characterization and waste acceptance. Frit formulations will be evaluated to optimize the capacity and throughput of the DWPF to determine the optimum aluminum content in sludge targeted for aluminum leaching.

\section{Hanford}

Currently, test work is proceeding at PNNL on the first of eight composite samples that will be evaluated for leaching and filtration behavior. Samples from multiple tanks with similar processing history have been identified out of the existing sample archive. Eight different groups have been identified based on processing history. Available samples from tanks within each processing group will be homogenized to produce a composite sample that will then be subjected to further characterization and testing.

Parametric tests over a range of processing conditions will be performed with seven of these composite (the last, group 8 , will be subjected to filtration testing only). These parametric tests will provide additional insight into the actual waste performance for boehmite (group 5), gibbsite (groups 3 and 4), phosphate (groups 1 and 7), and chromium (groups 2 and 6). 


\begin{tabular}{|l|l|}
\hline $\begin{array}{l}\text { Group } \\
\text { ID }\end{array}$ & Type \\
\hline 1 & Bi Phosphate sludge \\
\hline 2 & Bi Phosphate saltcake (BY, T) \\
\hline 3 & $\begin{array}{l}\text { Plutonium Uranium Extraction (PUREX) Cladding Waste } \\
\text { sludge }\end{array}$ \\
\hline 4 & Reduction Oxidation (REDOX) Cladding Waste sludge \\
\hline 5 & REDOX sludge \\
\hline 6 & S - saltcake (S) \\
\hline 7 & Tributyl phosphate (TBP) waste sludge \\
\hline 8 & FeCN wastes \\
\hline
\end{tabular}

In parallel, simulants for gibbsite, boehmite, chromium and filtration will be developed, tested and evaluated against existing actual waste characterization data. These simulants will then be used in additional parametric bench scale tests and eventually in a pilot scale demonstration of the leaching process.

\section{Technology Gaps}

Savannah River Site

A key parameter for the SRS process flow sheet is reduction of the waste storage volume for the leachate liquor and wash water. To keep the DWPF operating, the sludge must be retrieved from various tanks, prepared by washing, and tested for compatibility. With the limited tank storage space available, generating a large amount of leachate liquor and wash water is not feasible. A method for minimizing the storage volume is needed.

Analysis and testing of the six waste tanks targeted for aluminum leaching is needed to confirm baseline assumptions and determine process conditions (concentration, temperature, time). There are very minimal data on the ratios of gibbsite, boehmite, and other aluminum-containing phases in SRS waste, and minimal particle size data. Additionally, analysis of the actinide behavior during leaching is needed to ensure adequate margin in safety controls. Although testing and characterization of each waste tank is expected to be pursued, a fundamental understanding of the parameters that effect dissolution and actinide behavior would aid in optimizing process conditions. More complete characterization would also aid in developing more representative simulants as well.

There are numerous needs for process monitoring equipment for in-tank or online radioactive service. These include aluminum dissolution, solution density, sludge density, and settling rate. Current analysis techniques require removal of samples, or are not sufficiently precise to be very useful. These methods for improving the total sludge mass estimate would also aid in planning the DWPF schedule and improve the prediction of the facility life cycle and number of canisters.

Settling of the sludge after leaching and each wash step adds considerable duration to processing of each batch of sludge. The baseline assumes that two weeks are needed for settling after each step, but the basis for this duration is not well defined. Planned laboratory measurements of settling rates will improve the prediction of process durations and allow better planning, but a 
more generalized method of prediction would be useful. Use of an on-line measurement method would also help to confirm when the subsequent processing step can commence.

The impact of leaching on rheology is not known, and correlations with leaching, temperature, and speciation are needed. The ability to predict the rheological properties and throughput parameters related to DWPF would aid in the planning and decrease the need for tank-specific experiments.

Hanford

The most significant gap at Hanford is associated with the demonstration of the process performance at scale larger than bench top. To date, the leaching process has only been demonstrated at the bench top. While the underlying chemistry has been used at industrial scale for decades, deployment with the specific operating conditions and process equipment has not been done. To address this issue, the WTP has undertaken building an approximately $1 / 4$-scale version of the leaching process. Currently the system is being designed, and construction will be complete later this year.

\section{Conclusions}

Dissolution of aluminum from sludge wastes at SRS and Hanford is key to optimizing throughput of the HLW melters and minimizing the number of canisters of glass waste sent to the Repository. Many laboratory scale tests have been run on Hanford samples, and a few on SRS samples. One full-scale aluminum dissolution was successfully performed on waste at SRS in 1982 , but generated a very large quantity of liquid waste $(\sim 3,000,000$ gallons), and caused several operational issues. No large-scale tests have been done on Hanford wastes. Although the data to date give a generally positive indication that aluminum dissolution will work, many issues remain. Principal among these issues are the downstream impacts, with available liquid storage space critical at SRS, and LAW volumes for treatment and vitrification critical at Hanford. Better approaches are needed to deal with the waste volumes and limitations on disposal methods. This improvement requires a more extensive understanding of the kinetics of dissolution, as well as the factors that effect rates, effectiveness, and secondary species. Models of the dissolution rate that have been developed are useful, but suffer from limitations on applicable compositional ranges, mineral phases, and particle properties that are difficult to measure. Further data from testing are needed to improve the accuracy of the models, as well as to extend the range of conditions of applicability. How these other phases impact the dissolution, as well as the physical properties of the remaining sludge are critical to the processability of the waste through the vitrification processes. The converse challenge of preventing precipitation from leachate solutions in downstream processes also needs additional research. Chromium leaching at Hanford is also critically important to reducing the number of HLW canisters.

Interaction between the sites and researchers at the workshop was highly beneficial to develop an understanding of the issues surrounding aluminum and chromium leaching. The two sites have significantly different strategies for implementing aluminum dissolution, primarily because of differences in facilities and schedules. Although some needs overlap, some are very different (e.g. corrosion and temperature limits). Solutions to the needs can overlap in common areas, and there is a need for collaboration. A fundamental understanding of the dissolution rates and parameters that affect it are important for both sites. While there is a general understanding of 
the basics of aluminum dissolution, there are unknowns regarding downstream processes, facility throughput rates, and the impact of soluble and insoluble species. Chromium leaching at Hanford has been examined with several samples, but the fundamental chemistry and physical factors are not extensively known. Many waste tanks have not been sampled and analyzed for aluminum behavior and speciation, so there are numerous unknowns regarding the widespread effectiveness and consistency of leaching. At SRS, the estimated inventory of sludge has recently increased significantly, causing the aluminum leaching to become vital to meeting site treatment schedules. Methods to minimize the volume of stored leachate liquors are critical to maintaining Tank Farm and DWPF operations. At Hanford, methods are needed to minimize the amount of caustic used for dissolution, and to speed the dissolution, which are opposing goals when developing the chemistry of the process. While there is good likelihood of success in meeting the objectives at both sites, there is much work that needs to be done to ensure it.

\section{Appendix}

Workshop agenda

The agenda and presentations can be accessed at:

http://www.srs.gov/general/srnl/alcr/agenda.htm

\section{References}

Addai-Mensah, J., Aluminum Dissolution Kinetics in Caustic Media, a Literature Review, January 23, 2007, Workshop Presentation

Ator, R. A., In Tank Sludge Processing Demonstration Technical Summary, DPSP 83-17-14, September 13, 1984. D.K. Peeler, High Aluminum Wastes; Sludge Feed Preparation and Implications on Vitrification, WSRC-MS-200700012 .

Brown, K.G., R.L. Postles, T. Edwards, SME Acceptability Determination for DWPF Process Control, WSRC-TR95-364, Rev. 5, September, 2006.

Certa, P., T., Crawford, Aluminum and Chromium Leaching for HLW Sludge Workshop, January 23, 2007, CH2M32399-VA, Workshop Presentation.

Davis, N.R., SRS Site Needs, LWO-LWE-2007-00023, Workshop Presentation, January 23, 2007.

Eibling, R.E., "Tank 15H Aluminum Dissolving 1981 High Level Cells Tests", DPST-82-788, August 19, 1982.

Fondeur, F.F., Hobbs, Fink, S., Aluminum Leaching of “Archived” Sludge from Tanks 8F, 11H, and 12H, WSRCTR-2004-00180, March 12, 2004

Gbor, P.K.; Jia, C.Q. Critical evaluation of coupling particle size distribution with the shrinking core model. Chem. Eng. Sci. 2004, 59, 1979-1987

Gillam, J., H. Shah, M. Rios-Armstrong, Sludge Batch Plan, CBU-PIT-2005-00144, Rev. 1.August 7, 2006.

Gillam, J. M., Aluminum in Waste Tank Sludge: History and Status, CBU-PIT-2006-00068, July 11, 2006b,

Gilbert, R., Caustic and Oxidative Leaching to Solubilize Aluminum and Chromium, January 23, 2007 Workshop presentation. 
Hamm, B.A., H.H. Elder, Savannah River Site Sludge Characterization Model Using Dial-up Factors, CBU-PIT2006-00058, March 28, 2006.

Hill, P., B. Hamm, Sludge Mass Estimate - Update, January 23, 2007, Workshop Presentation.

Levenspiel O. Chemical Reaction Engineering, 3rd Edition; Wiley: New York, 1999.

Jones, D.W., "Tank 11 Sludge Aluminum Dissolving Tests", DPST-81-328, March 17, 1981

Lumetta, G.J.; Carson, K.J.; Darnell, L.P.; Greenwood, L.R.; Hoopes, F.V.; Sell, R.L.; Sinkov, S.I.; Soderquist, C.Z.; Urie, M.W.; Wagner, J.J. Caustic Leaching of Hanford Tank S-110 Sludge. PNNL-13702; Pacific Northwest National Laboratory: Richland, WA, 2001.

Lumetta, G.J.; Burgeson, I.E.;Wagner, M.J.; Liu, J.; Chen, Y.L. Washing and Leaching of Hanford Tank Sludge: Results of FY1997 Studies. PNNL 11636; Pacific Northwest National Laboratory: Richland, WA, 1997.

Lumetta, G.J.; Rapko, B.M.; Wagner, M.J.; Liu, J.; Chen, Y.L. Washing and Caustic Leaching of Hanford Tank Sludges: Results of FY 1996 Studies. PNNL-11278; Pacific Northwest National Laboratory: Richland, WA, 1996.

Lumetta, G.J.; Rapko, B.M. Washing and Alkaline Leaching of Hanford Tank Sludges: A Status Report. PNL10078; Pacific Northwest National Laboratory: Richland, WA, 1994.

Lumetta, G.J., B.M. Rapko, J. Liu, and D.J. Temer. "Enhanced Sludge Washing for Pretreating Hanford Tank Sludges," in Science and Technology for Disposal of Radioactive Tank Wastes, W. W. Schulz and N. J. Lombardo, eds., Plenum Press, New York, 1998, pp. 203-218.

Lumetta, G.J.; Rapko, B.M.; and Liu, J. Washing and Caustic Leaching of Hanford Tank Sludge: Results of FY 1998 Studies. PNNL-12026; Pacific Northwest National Laboratory: Richland, WA, 1998.

Meacham, J.E., Aluminum Wash and Leach Factors, RPP-11079 Rev 0, CH2MHILL Hanford Group, July 2003.

Nash, K.L., L.R. Martin, R. Witty, L. Rao, W. Reed, B. Powell, Actinides in Alkaline Oxidizing Media: Species Relevant to Tank Waste Pretreatment, January 24, 2007, workshop presentation.

Pajunen, A. L., Evaluation of Boehmite Dissolution Kinetics in Tank Waste, LWO-PIT-2006-00006, September 28, 2006.

Palanori, J. L., and Y. K. Kharaka, 2004, A Compilation of Rate Parameters of Water-Mineral Interaction Kinetics for Application to Geochemical Modeling, Report 2004-1068, U.S. Geological Survey, U.S. Department of the Interior, Washington D.C.

Peeler, D.K., High Aluminum Wastes: Sludge Feed Preparation and Implications on Vitrification, WSRC-MS-200700012, January 24, 2007, workshop presentation.

Perez, J. M., D.F. Bickford, D.E. Day, D.S. Kim, S.L. Lambert, S.L. Marra, D.K. Peeler, D.M. Strachan, M.B. Triplett, J.D. Vienna, R.S. Wittman, High-Level Waster Melter Study Report, PNNL-13582, July, 2001. Rapko, B.M., G.J. Lumetta, Status Report on Phase Identification in Hanford Tank Sludges, PNNL-13394, 2000.

Peterson, R.A., G.J. Lumetta, B.M Rapko, A.P. Poloski, Modeling of Boehmite Leaching from Actual Hanford High-Level Waste Samples, Sep. Sci. Tech. In Press.

Pike, J.A., Preliminary Aluminum Dissolution Flowsheet, LWO-PIT-2006-00068, Rev. 0, November 17, 2006.

Rapko, B.M., G.J. Lumetta, Status Report on Phase Identification in Hanford Tank Sludges, PNNL-13394, December, 2000.

Scotford, R.F.; Glastonb, Jr. Effect of Temperature on Rates of Dissolution of Gibbsite and Boehmiite. Canadian J. Chem. Eng. 1971, 49 (5) 611. 
Scotford, R.F.; Glastonb, Jr. Effect of Concentration on Rates of Dissolution of Gibbsite and Boehmite. Canadian J. Chem. Eng. 1972, 50 (6) 754-758.

Skoufadis, C; Panias, D; Paspaliaris, I. Kinetics of boehmite precipitation from supersaturated sodium aluminate solutions. Hydrometallurgy, 2003, 60 (68) 57-68.

Smith, L.T., T. Ruff, V. Phillips, M. Jung, R. Toghiani, J. Lindner, Aluminum Solubility, January 23, 2007 Workshop presentation.

Spencer, B.B., J.L. Collins, R.D. Hunt, Caustic Leaching of SRS Tank 12H Sludge with and without Chelating Agents, ORNL/TM-2002/195, April, 2003

Temer D. J. and R. Villarreal, Sludge Washing and Alkaline Leaching Tests on Actual Hanford Tank Sludge: A Status Report, LAUR -95-2070

Temer D. J. and R. Villarreal, Sludge Washing and Alkaline Leaching Tests on Actual Hanford Tank Sludge: FY 1996 Results, LAUR -96-2839

Temer D. J. and R. Villarreal, Sludge Washing and Alkaline Leaching Tests on Actual Hanford Tank Sludge: FY 1997 Results", LAUR -97-2889

Ullmann's Encyclopedia of Industrial Chemistry, $6^{\text {th }}$ Edition, v. 2, p. $349-367$, Wiley-VCH, c. 2003.

Woolsey, G.B., R.M. Galloway, M.J. Plodinec, W.L. Wilhite, and J.R. Fowler, "Processing of Tank 15 Sludge", DPST-80-361, June 30, 1980 
Appendix

Workshop Agenda

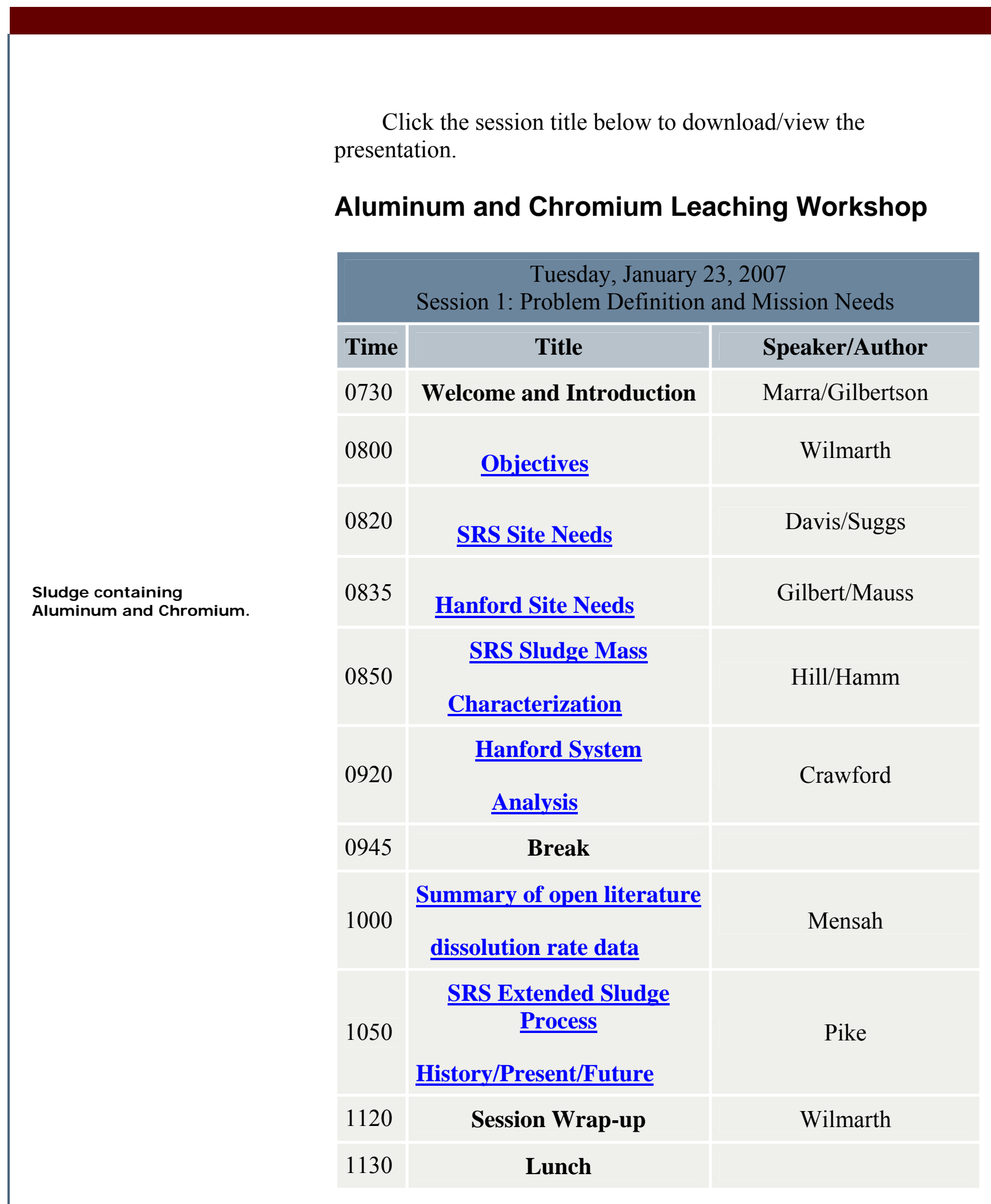




\begin{tabular}{|c|c|c|}
\hline \multicolumn{3}{|c|}{$\begin{array}{l}\text { Tuesday, January 23, } 2007 \\
\text { Session 2: Testing Data and Interpretation }\end{array}$} \\
\hline Time & Title & Speaker/Author \\
\hline 1230 & $\underline{\text { Session Objectives }}$ & Wilmarth \\
\hline 1245 & Aluminum Solubility & Smith \\
\hline 1315 & $\begin{array}{l}\frac{\text { Hanford Boehmite/Chrome }}{\text { Dissolution rate data and }} \\
\text { future test plans }\end{array}$ & Peterson/Barnes \\
\hline 1415 & Break & \\
\hline 1500 & $\begin{array}{c}\frac{\text { SRS Dissolution rate testing }}{\text { on } 8 \mathrm{~F}, 11 \mathrm{H}, 12 \mathrm{H}, \text { and }} \\
\underline{15 \mathrm{H}}\end{array}$ & Hobbs \\
\hline 1530 & $\underline{\text { Kinetic Studies }}$ & Polestar \\
\hline 1600 & $\begin{array}{l}\text { U/Pu Chemistry during } \\
\text { Leaching }\end{array}$ & Nash \\
\hline 1630 & $\begin{array}{l}\text { Panel Discussion on Data } \\
\text { Interpretation and } \\
\text { Implications }\end{array}$ & Pike/Peterson/Fink \\
\hline 1715 & Session Wrap-up & Wilmarth \\
\hline \multicolumn{3}{|c|}{$\begin{array}{c}\text { Wednesday -- January 24, } 2007 \\
\text { Session 3: Ongoing Research/Current Studies }\end{array}$} \\
\hline Time & Title & Speaker/Author \\
\hline 0730 & $\underline{\text { Sessions Objective }}$ & Wilmarth \\
\hline 0745 & $\underline{\text { ART Proposal Awards }}$ & Geniesse \\
\hline 0815 & $\begin{array}{l}\text { Alternative Oxidation } \\
\text { Leaching Studies }\end{array}$ & Holland \\
\hline
\end{tabular}




\begin{tabular}{|c|c|c|}
\hline 0845 & $\begin{array}{c}\text { Increasing Metals Content } \\
\underline{\text { of Glasses }}\end{array}$ & Peeler \\
\hline 0930 & Session Wrap-up & Wilmarth \\
\hline 0945 & Break & \\
\hline \multicolumn{3}{|c|}{$\begin{array}{l}\text { Wednesday -- January 24, } 2007 \\
\text { Session 4: Research and Development } \\
\text { Path Forward }\end{array}$} \\
\hline Time & Title & Speaker/Author \\
\hline 1000 & $\underline{\text { Session Objectives }}$ & Wilmarth \\
\hline 1015 & WTP R\&D Plan & Peterson/Barnes \\
\hline 1045 & SRS R\&D Plans & Pike \\
\hline 1130 & $\begin{array}{c}\text { Senior Management Panel } \\
\text { Discussion on Technology } \\
\text { Roadmap }\end{array}$ & Dickert/Barnes/Gilbertson \\
\hline 1215 & Session Wrap-up & Wilmarth \\
\hline 1230 & Lunch & \\
\hline 1330 & $\begin{array}{c}\text { Roles and Responsibilities } \\
\text { for Status Paper }\end{array}$ & Wilmarth \\
\hline 1345 & Open Discussion & \\
\hline 1430 & Adjourn & \\
\hline
\end{tabular}

Please take a few moments to complete our brief feedback form about the workshop and email it to rosalind.blocker@srs.gov.

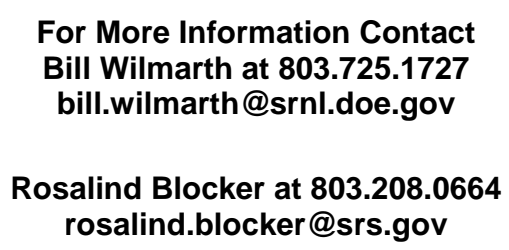


WSRC-STI-2007-00168

April 25, 2007

Sponsored by the Department of Energy and Washington Savannah River Company

Last updated: February 5, 2007 